\title{
Absorção de água em argamassa leve com a incorporação de poliestireno expandido
}

Water absorption of the lightweight mortar with expanded polystyrene

\author{
M. W. M. Silva ${ }^{1 *}$; C. M. Azevedo²; L. S. Farias²; E. M. R. Gomes²; L. N. P. \\ Cordeiro $^{2}$
}

\author{
${ }^{1}$ Programa de Pós-Graduação em Infraestrutura e Desenvolvimento energético/ NDAE, Universidade Federal do \\ Pará, 68464-000, Tucuruí-Pará, Brasil. \\ ${ }^{2}$ Faculdade de Engenharia Civil/Instituto de Tecnologia/Universidade Federal do Pará, 68464-000, Belém-Pará, \\ Brasil. \\ *max_weverton19@hotmail.com
}

(Recebido em 03 de outubro de 2019; aceito em 21 de fevereiro de 2020)

\begin{abstract}
Este artigo apresenta o efeito da incorporação do poliestireno expandido (EPS) na resistência e durabilidade de argamassas leves. Foram investigadas as propriedades de durabilidade, por meio dos ensaios de absorção por capilaridade e absorção de água por imersão. No estado endurecido, analisou-se também a resistência à compressão e a densidade de massa. Para isso, produziu-se argamassas com traços de cimento/areia de 1:4,5, 1:5 e 1:6 e com teores de incorporação de EPS 0\%, 20\% e 30\%, em volume. Os resultados demonstram que as argamassas leves com EPS apresentam melhores propriedades de durabilidade que as argamassas convencionais, uma vez que obtiveram menor absorção de água comparadas as de referência. Por outro lado, essas argamassas possuem resistência à compressão inferior as tradicionais.

Palavras-chave: Argamassa leve, Poliestireno expandido, Absorção de água.
\end{abstract}

This paper presents the effect of incorporating expanded polystyrene (EPS) on the strength and durability of lightweight mortars. Durability properties were investigated by capillary water absorption and immersion water absorption tests. In the hardened state, the compressive strength and mass density were also analyzed. For this, mortars were produced with traces of cement / sand of 1: 4,5, 1:5 and 1: 6 and with incorporation contents of $0 \%, 20 \%$ and $30 \%$ by volume. The results showed that lightweight mortars with EPS have better durability properties than conventional mortars, since they obtained less water absorption compared to the reference ones. On the other hand, these mortars have lower compressive strength than traditional ones.

Keywords: lightweight mortar, polystyrene expanded, water absorption.

\section{INTRODUÇÃO}

A produção de concretos e argamassas de densidade convencional é composta de agregados naturais, cimento e água, basicamente. E a utilização desses recursos naturais gera elevada degradação ao meio ambiente, o que tem motivado as pesquisas por materiais reciclados e alternativos para substituir os agregados. Esse uso de materiais alternativos reduz a demanda por recursos naturais, assim como a quantidade de resíduos depositados em aterros [1].

O poliestireno expandido é um material inerte de natureza hidrofóbica que tende a segregar em concretos ou argamassas [1]. Para evitar que ocorra essa segregação, pesquisas anteriores mostraram que o uso de sílica ativa e superplastificante melhorou a zona de transição entre o agregado leve e a pasta, assim como proporcionou uma melhor distribuição ao longo da argamassa $[2,3]$.

A durabilidade de concretos e argamassas submetidos a ambientes agressivos depende, em grande parte, da capacidade de penetração desses agentes para o interior da estrutura. Esse mecanismo de transporte está diretamente relacionado com as características dos poros. Pode-se dizer que essa penetração é descrita por três sistemas de transporte: (1) permeabilidade, (2) difusão e (3) absorção. A permeabilidade é a medida do fluxo de água sob um gradiente de pressão, enquanto a difusão é o movimento de íons devido a uma concentração gradiente. A absorção pode ser descrita como a capacidade de materiais de absorver água por sucção capilar [4].

A absorção de água por capilaridade é uma das propriedades que regem o transporte de íons para o interior do concreto. Ela é um parâmetro fundamental para quantificar a durabilidade em 
compostos cimentícios [5, 6]. A absorção depende de muitos fatores, incluindo: (a) proporção de materiais na mistura; b) a presença de aditivos químicos e de materiais cimentícios suplementares; c) a composição e as características físicas dos componentes cimentícios e dos agregados; d) teor de ar incorporado; e) o tipo e a duração da cura; f) o grau de hidratação ou idade; g) a presença de microfissuras; h) a presença de tratamento de superfície, como a presença de selantes; e i) método de aplicação, incluindo consolidação e acabamento [4].

Pesquisas anteriores mostram uma tendência de concretos leves com poliestireno expandido serem melhores em relação a durabilidade do que os convencionais [1]. Se tratando de concretos leves, Elsharief et al. (2005) [7] constatou uma menor absorção capilar. Ferrándiz-Mas e GarcíaAlcocel (2013) [6], por outro lado, observaram a redução significativa da absorção em argamassas contendo poliestireno expandido. Nesse mesmo sentido, o trabalho de Torres et al. (2009) [9] constatou uma forte relação entre a densidade de concretos leves e a sua absorção.

Além da redução da densidade final, o uso do EPS em matrizes cimentícias pode ser eficaz para evitar o surgimento de algumas patologias, como a umidade ascensional em elementos construtivos que possuem contato direto com a água ou com o solo. Desse modo, este trabalho busca avaliar o efeito da absorção de água por capilaridade em argamassas leves em diferentes teores de incorporação, assim como em traços com distintos consumos de cimento.

\section{MATERIAL E MÉTODOS}

O programa experimental tem por objetivo contribuir para o estudo das propriedades de durabilidade das argamassas leves, por meio de ensaios que avaliam a absorção de água. Sendo assim, foram determinadas a absorção de água por capilaridade, segundo a Norma Brasileira (NBR) 9779 [10] e a absorção de água por imersão, de acordo com a norma NBR 9778 [11]. Para complementar o estudo, foram determinadas a densidade de massa das argamassas leves, conforme a NBR 9778 [11], e o ensaio de resistência à compressão, realizado com os corpos de prova cilíndricos $(5 \mathrm{~cm} \times 10 \mathrm{~cm})$ usados nos ensaios de absorção. As argamassas produzidas foram submetidas a cura submersa e ensaiadas na idade de 28 dias.

Os materiais usados neste trabalho foram: cimento Portland composto com escória de alto forno, tipo CP II E - 32; agregado miúdo natural, com dimensão máxima de $600 \mu \mathrm{m}$; sílica ativa, com composição de $\mathrm{SiO}_{2}$ de 93,9\%; aditivo superplastificante e pérolas de poliestireno expandido com diâmetro de até $3 \mathrm{~mm}$. Os valores de massa específica desses materiais são descritos na Tabela 1.

Tabela 1 - Massa específica dos materiais utilizados.

\begin{tabular}{ccccc}
\hline $\begin{array}{c}\text { Cimento } \\
\left(\mathbf{g} / \mathbf{c m}^{\mathbf{3}}\right)\end{array}$ & $\begin{array}{c}\text { Sílica } \\
\left(\mathbf{g} / \mathbf{c m}^{\mathbf{3}}\right)\end{array}$ & $\begin{array}{c}\text { Areia } \\
\left(\mathbf{g} / \mathbf{c m}^{\mathbf{3}}\right)\end{array}$ & $\begin{array}{c}\text { EPS } \\
\left(\mathbf{g} / \mathbf{c m}^{\mathbf{3}}\right)\end{array}$ & $\begin{array}{c}\text { Aditivo } \\
\left(\mathbf{g} / \mathbf{c m}^{\mathbf{3}}\right)\end{array}$ \\
\hline 3,1 & 2,25 & 2,61 & 0,015 & 1,09 \\
\hline
\end{tabular}

Para isso, o experimento consistiu em uma argamassa produzida sem a incorporação do EPS, tomada como referência, e outra argamassa produzida com a incorporação de poliestireno expandido, em dois teores de incorporação, $20 \%$ e 30\%, em relação ao volume total de materiais.

Foram usadas relações de aglomerante/agregado miúdo (1:m) de 1:4,5, 1:5 e 1:6, resultando em misturas com baixo consumo de cimento. Em cada traço, a sílica ativa foi empregada na proporção de $10 \%$ do peso do cimento. Devido ao alto teor de finos na composição dos traços, com o aglomerante, sílica e uma areia fina, a quantidade de superplastificante foi fixada em 3,5\%, para evitar altos consumos de água. Desse modo a quantidade de água na mistura ficou vinculada ao índice de consistência, fixado em $240 \mathrm{~mm} \pm 10 \mathrm{~mm}$, segundo a norma NBR 13276 [12].

Desse modo, foram obtidas 15 misturas, conforme apresentado Tabela 2. A representação de cada mistura é dada pela letra $\mathrm{T}$, para indicar o traço, seguido do consumo de areia, teor de incorporação de poliestireno expandido e, por último, caso tenha, o percentual do EPS usado. Assim, por exemplo, "T 4,5 20\%" indica um traço de 1:4,5, com 20\% de EPS, em volume. 
Tabela 2 - Consumo de materiais em $\mathrm{kg} / \mathrm{m}^{3}$.

\begin{tabular}{lcccccc}
\hline Traço & $\begin{array}{c}\text { Cimento } \\
\left(\mathbf{k g} / \mathbf{m}^{\mathbf{3}}\right)\end{array}$ & $\begin{array}{c}\text { Sílica } \\
\left(\mathbf{k g} / \mathbf{m}^{\mathbf{3}}\right)\end{array}$ & $\begin{array}{c}\text { Areia } \\
\left(\mathbf{k g} / \mathbf{m}^{\mathbf{3}}\right)\end{array}$ & $\begin{array}{c}\text { EPS } \\
\left(\mathbf{k g} / \mathbf{m}^{\mathbf{3}}\right)\end{array}$ & $\begin{array}{c}\text { Água } \\
\left(\mathbf{l} / \mathbf{m}^{\mathbf{3}}\right)\end{array}$ & $\begin{array}{c}\text { Aditivo } \\
\left(\mathbf{k g} / \mathbf{m}^{\mathbf{3}}\right)\end{array}$ \\
\hline T 4,5 0\% & 359,59 & 35,96 & 1618,16 & 0,00 & 244,24 & 12,59 \\
\hline T 4,5 20\% & 287,09 & 28,71 & 1291,91 & 3,40 & 194,40 & 10,05 \\
\hline T 4,5 30\% & 246,30 & 24,63 & 1108,37 & 4,97 & 186,35 & 8,62 \\
\hline T 5 0\% & 330,77 & 33,08 & 1653,83 & 0,00 & 241,46 & 11,58 \\
\hline T 5 20\% & 262,42 & 26,24 & 1312,08 & 3,24 & 205,56 & 9,18 \\
\hline T 5 30\% & 368,87 & 36,89 & 1844,35 & 7,96 & 279,91 & 12,91 \\
\hline T 6 0\% & 293,28 & 29,33 & 1759,65 & 0,00 & 215,07 & 10,26 \\
\hline T 6 20\% & 225,40 & 22,54 & 1352,42 & 3,55 & 185,33 & 7,89 \\
\hline T 6 30\% & 208,12 & 20,81 & 1248,70 & 4,41 & 180,37 & 7,28 \\
\hline
\end{tabular}

A mistura dos materiais foi dada a partir de uma adaptação da ABNT NBR 16541 (2016) [13], pois o EPS foi incluso na mistura após uma primeira homogeneização do restante dos materiais, com velocidade de rotação em torno do eixo de $140 \mathrm{rpm}$. Com isso, o preparo da argamassa seguiu conforme fluxograma apresentado na Figura 1. Adotou-se como índice de consistência para esta argamassa o valor de $240 \mathrm{~mm} \pm 10 \mathrm{~mm}$, valor ao qual garante-se uma fluidez da argamassa e não ocorre segregação do EPS na matriz. O índice foi medido segundo procedimento descrito na ABNT NBR 13276 (2005) [10].

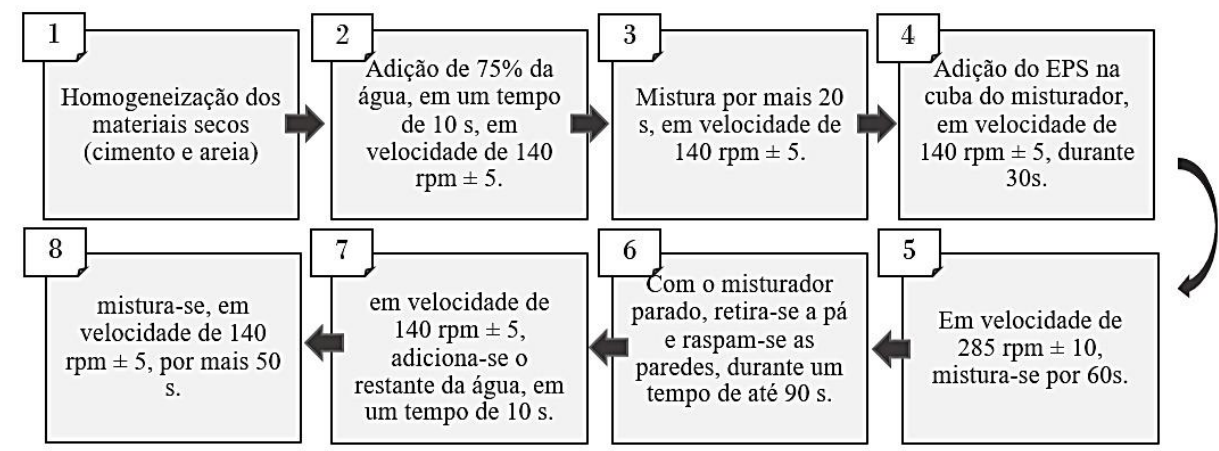

Figura 1 - Fluxograma de atividades para produção da argamassa.

\section{RESULTADOS E DISCUSSÃO}

O uso do EPS como agregado nas misturas de argamassa teve papel significativo na redução de sua densidade de massa, uma vez que foi possível obter compósitos em que a redução da massa específica da amostra seca foi de até $29 \%$, em relação ao traço de referência (Tabela 2). É possível observar uma redução percentual da massa específica $\left(\mathrm{m}_{\text {esp }}\right)$, aproximadamente, proporcional ao teor de incorporação do poliestireno expandido para os diferentes traços em estudo.

Tabela 2 - Densidade de massa da argamassa leve.

\begin{tabular}{lccccccccc}
\hline & $\mathrm{T} 4,5$ & $\mathrm{~T} 4,5$ & $\mathrm{~T} 4,5$ & $\mathrm{~T} 5$ & $\mathrm{~T} 5$ & $\mathrm{~T} 5$ & $\mathrm{~T} 6$ & $\mathrm{~T} 6$ & $\mathrm{~T} 6$ \\
& $0 \%$ & $20 \%$ & $30 \%$ & $0 \%$ & $20 \%$ & $30 \%$ & $0 \%$ & $20 \%$ & $30 \%$ \\
\hline $\mathrm{m}_{\text {esp }}$ amostra seca $\left(\mathrm{g} / \mathrm{cm}^{3}\right)$ & 1,94 & 1,58 & 1,32 & 1,92 & 1,63 & 1,55 & 1,97 & 1,60 & 1,51 \\
\hline $\mathrm{m}_{\text {esp }}$ sat. $\left(\mathrm{g} / \mathrm{cm}^{3}\right)$ & 2,09 & 1,66 & 1,44 & 2,10 & 1,73 & 1,64 & 2,10 & 1,68 & 1,59 \\
\hline $\mathrm{m}_{\text {esp. }}$ real $\left(\mathrm{g} / \mathrm{cm}^{3}\right)$ & 2,28 & 1,75 & 1,50 & 2,35 & 1,81 & 1,70 & 2,27 & 1,74 & 1,65 \\
\hline
\end{tabular}

Os resultados do ensaio de resistência à compressão estão apresentados na Figura 2. Esses dados corroboram os de pesquisas anteriores, uma vez que a resistência das argamassas leves reduziu conforme a aumento do teor de poliestireno expandido, assim como ocorre com a densidade (Figura 3) $[14,15,16]$. Para os três traços estudados, a influência da adição de EPS na resistência à compressão ocorre de modo similar, visto que o EPS tem natureza inerte, flexível e que não possui resistência mecânica, atuando como vazios ao longo da matriz. 


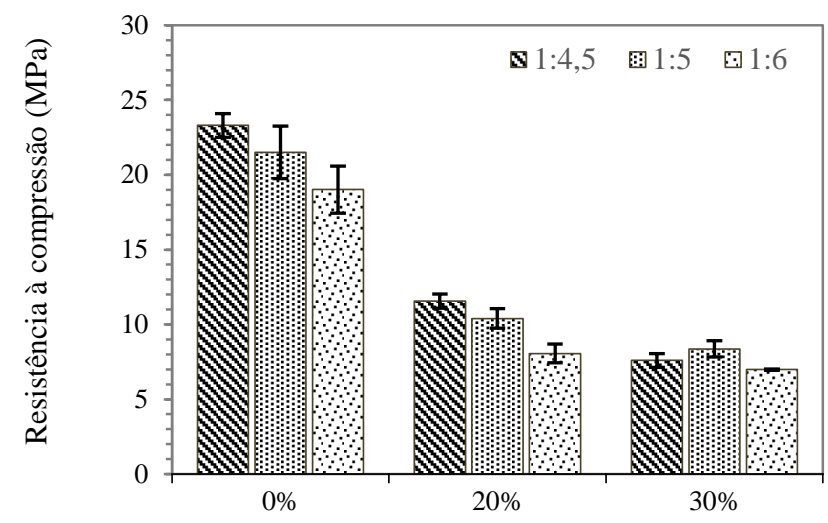

Figura 2 - Resistência à compressão.

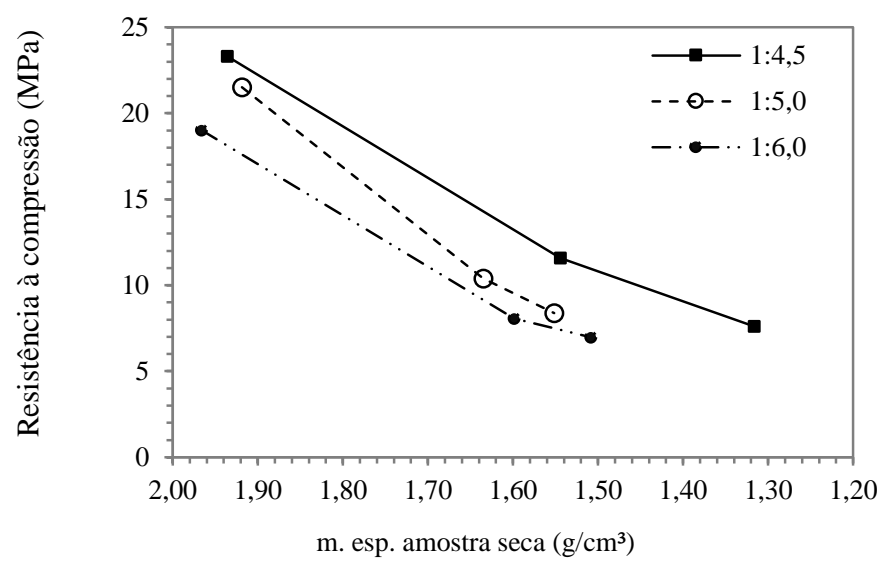

Figura 3 - Resistência à compressão x massa específica.

A Tabela 3 apresenta os resultados de absorção de água por capilaridade dos traços controles, assim como os dos traços com poliestireno expandido. Pode-se notar uma redução considerável da absorção de água capilar nas argamassas leves. Estudos anteriores mostram essa tendência [2, 8]. Destaca-se nesse processo que a combinação EPS e sílica ativa na matriz cimentícia proporcionou essa redução da porosidade e, consequentemente, da absorção, sendo que foi utilizado um teor fixo de $10 \%$ para todos os traços. Isso se deve ao fato de que a sílica, por ser extremamente fina, atua como microfiller, preenchendo dessa forma os vazios deixados durante a reação de hidratação do cimento e o EPS por apresentar natureza hidrofóbica. Durante o processo de realização da argamassa, podemos colocar como um fato que também colaborou para esta redução da absorção é a relação água materiais secos,

Tabela 3 - Absorção de água por capilaridade em gramas por centímetro quadrado $\left(\mathrm{g} / \mathrm{cm}^{2}\right)$.

\begin{tabular}{cccccccccc}
\hline $\begin{array}{c}\text { Tempo } \\
\text { (h) }\end{array}$ & $\begin{array}{c}\text { T4,5 } \\
\mathbf{0 \%}\end{array}$ & $\begin{array}{c}\mathbf{T 4} \text { 4,5 } \\
\mathbf{2 0 \%}\end{array}$ & $\begin{array}{c}\mathbf{T 4 , 5} \\
\mathbf{3 0 \%}\end{array}$ & T5 0\% & T5 20\% & T5 30\% & T6 0\% & T6 20\% & T6 30\% \\
\hline $\mathbf{0}$ & 0,00 & 0,00 & 0,00 & 0,00 & 0,00 & 0,00 & 0,00 & 0,00 & 0,00 \\
\hline $\mathbf{3}$ & 0,19 & 0,05 & 0,10 & 0,24 & 0,11 & 0,11 & 0,19 & 0,04 & 0,13 \\
\hline $\mathbf{6}$ & 0,26 & 0,06 & 0,11 & 0,30 & 0,14 & 0,13 & 0,24 & 0,05 & 0,15 \\
\hline $\mathbf{2 4}$ & 0,48 & 0,11 & 0,17 & 0,50 & 0,22 & 0,19 & 0,37 & 0,09 & 0,19 \\
\hline $\mathbf{4 8}$ & 0,58 & 0,12 & 0,18 & 0,60 & 0,25 & 0,20 & 0,41 & 0,09 & 0,22 \\
\hline $\mathbf{7 2}$ & 0,62 & 0,13 & 0,19 & 0,64 & 0,27 & 0,22 & 0,44 & 0,10 & 0,23 \\
\hline
\end{tabular}

A elevada redução da absorção capilar pode ser relacionada ao corte da comunicação entre os poros capilares da argamassa, uma vez que as pérolas de poliestireno expandido atuaram como barreira a essa absorção. Por outro lado, o fato de o EPS ser um material hidrofóbico implica na 
formação de uma zona de transição entre a pasta e o agregado leve, a qual pode funcionar como caminho preferencial para absorção capilar (Figura 4) [17].

$\mathrm{Na}$ figura 4, são apresentadas imagens de Microscopia Eletrônica de Varredura. É possível identificar nela três fases distintas do compósito, a região do poliestireno expandido (que é formado por células fechadas, com uma cor escura), a da argamassa (na qual é possível visualizar grãos de areia e a pasta, com uma cor clara mais clara) e a zona de transição entre os dois materiais.

Nesse comportamento de redução da porosidade, Pires (2017) [18] observou que a incorporação de EPS reduz a absorção capilar, mas essa redução é proporcional ao teor incorporado até um determinado valor, a partir do qual o aumento do teor de EPS passa a aumentar a absorção de água. Esse comportamento foi constatado para as argamassas dos traços T4,5 e T6, uma vez que as argamassas com $20 \%$ tiveram menor taxa de absorção capilar que as demais. Em relação as argamassas do traço T5, observou-se que as argamassas com $20 \%$ e $30 \%$ tiveram valores de absorção capilar muito próximos, sendo que a argamassa T5 30\% obteve menor taxa de absorção.
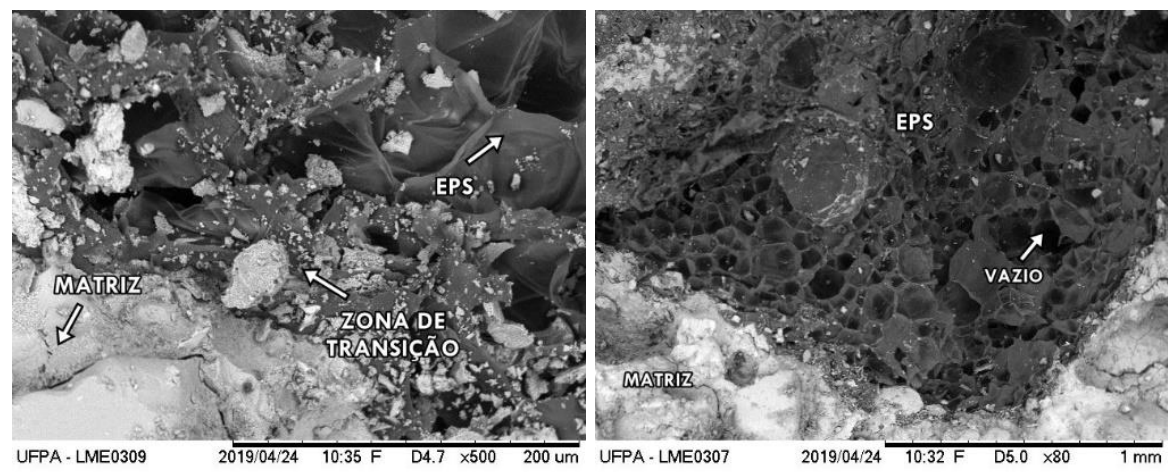

Figura 4 - Microscopia Eletrônica de Varredura (MEV) dos compósitos com poliestireno expandido.

Desse modo, o comportamento predominante permite definir que, quanto maior o teor de incorporação, maior será a área superficial da pérola de EPS e, consequentemente, maior a zona de transição. Isso explica o fato das argamassas com 30\% resultarem em maior absorção de água por capilaridade, como mostra a Figura 5.

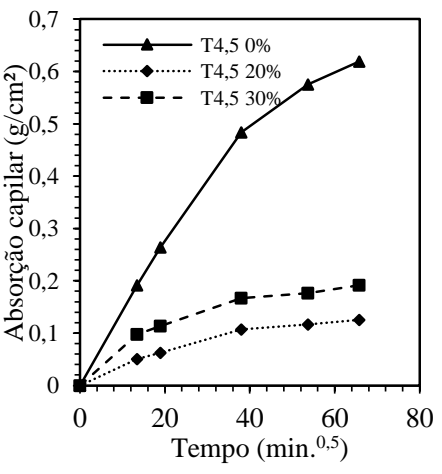

(a)

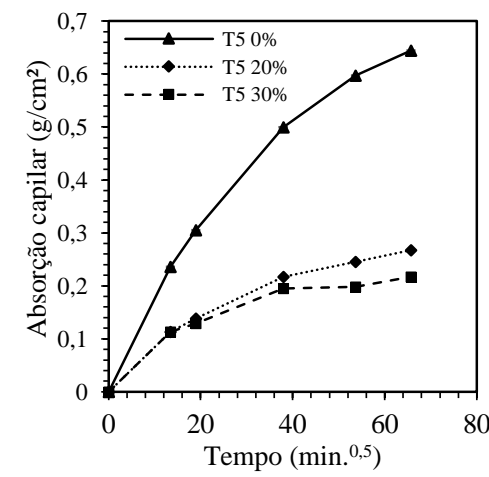

(b)

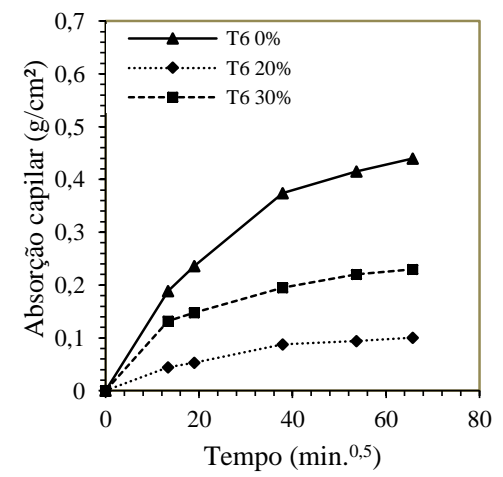

(c)

Figura 5 - Absorção de água capilar ao longo do tempo para os traços (a) 1:4,5, (b) 1:5 e (c) 1:6.

Nesse mesmo sentido, é observado que os resultados do ensaio de absorção de água por imersão tiveram resultados similares aos do ensaio de capilaridade (Figura 6). Para os traços da família $1: 4,5$, houve uma redução média de $44 \%$ na absorção de água por imersão, para o teor de $20 \%$ de EPS, e de $30 \%$, para a argamassa com o teor $30 \%$ de incorporação. Por outro lado, as argamassas leves dos traços da família 1,5 , com os teores de $20 \%$ e $30 \%$ de EPS, resultaram numa redução da absorção média de $38 \%$ e $37 \%$, respectivamente. Por fim, alcançou-se uma redução percentual na absorção de água por imersão de $24 \%$ e $17 \%$, para os traços de $20 \%$ e $30 \%$ da família 1:6. Assim, é possível notar que a absorção de água por imersão é menor para os traços com teores de incorporação de $20 \%$, isso ratifica o efeito do poliestireno expandido sobre a absorção de água. 

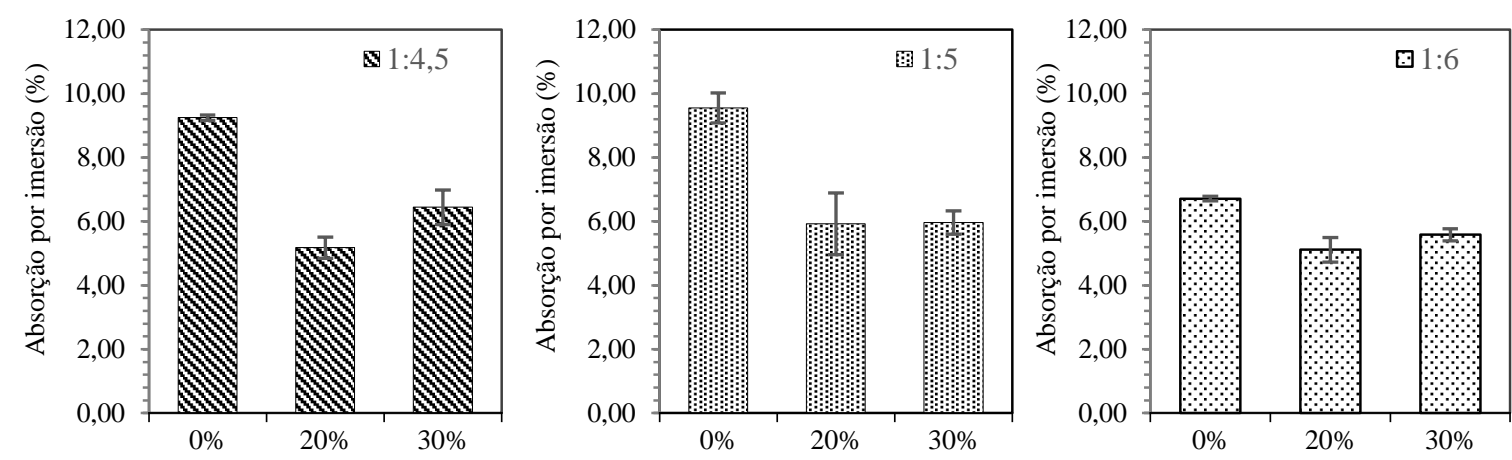

Figura 6-Resultados do ensaio de absorção por imersão dos traços 1:4,5, 1:5 e 1:6.

\section{CONCLUSÃO}

As argamassas com incorporação de poliestireno expandido (EPS) possuem menor massa específica que as argamassas convencionais e, consequentemente, possuem resistência à compressão inferior a essas.

Houve uma significativa queda na absorção por capilaridade dos traços contendo EPS, fato mais evidente nas argamassas com teores de poliestireno de $20 \%$. Nesse mesmo sentido, houve uma taxa de redução similar para os diferentes traços, 1:4,5, 1:5 e 1:6.

Os resultados do ensaio de absorção por imersão ratificam os resultados obtidos no ensaio de absorção por capilaridade, uma vez que houve queda na absorção de água para os dois experimentos.

\section{REFERÊNCIAS BIBLIOGRÁFICAS}

1. Khatib JM, Herki BA, Elkordi A. Use of Recycled Plastics in Eco-efficient Concrete. 1st ed. Woodhead Publishing; 2019. Chapter 7, Characteristics of concrete containing EPS. p. 137-165, doi:10.1016/b9780-08-102676-2.00007-4.

2. Babu KG, Babu DS, Behaviour of lightweight expanded polystyrene concrete containing silica fume. Cement Concrete Res. 2003 May;33(5):755-762, doi:10.1016/S0008-8846(02)01055-4.

3. Liu N, Chen B, Experimental study of the influence of EPS particle size on the mechanical properties of EPS lightweight concrete. Constr Build Mater. 2014 Oct;68:227-232, doi: 10.1016/j.conbuildmat.2014.06.062.

4. ASTM C1585. Standard Test Method for Mesurement of Rate Absorption of Water by Hydraulic-Cement Concretes. ASTM Int. 2004;4(147):1-6.

5. Neithalath N. Analysis of moisture transport in mortars and concrete using sorption-diffusion approach. ACI Mater J. 2006 May;103(3):209-217.

6. Bentz DP, Ehlen MA, Ferraris CF, Garboczi EJ, Sorptivitybased service life predictins for concrete pavements, Proceedings of the 7th International Conference on Concrete Pavements, p. 181-193, 2001.

7. Elsharief A, Cohen MD, Olek J, Influence of lightweight aggregate on the microstructure and durability of mortar. Cement Concrete Res. 2005 Jul; 35(7):368-1376, doi: 10.1016/j.cemconres.2004.07.011.

8. Ferrándiz-Mas V, García-Alcocel E, Durability of expanded polystyrene mortars. Constr Build Mater. 2013 Sep;46:175-182, doi: 10.1016/j.conbuildmat.2013.04.029.

9. Torres ML, García-Ruiz PA. Lightweight pozzolanic materials used in mortars: Evaluation of their influence on density, mechanical strength and water absorption. Cement Concrete Comp. 2009 Feb;31(2):114-119, doi: 10.1016/j.cemconcomp.2008.11.003.

10. ABNT NBR 9779. Argamassa e concreto endurecidos - Determinação da absorção de agua por capilaridade Assoc. Bras. Normas Técnicas, 2012.

11. ABNT NBR 9778. Argamassa e concreto endurecidos - Determinação da absorção de água por imersão - Índice de vazios e massa específica, Assoc. Bras. Normas Técnicas, 2005.

12. ABNT NBR 13276. Argamassa para assentamento e revestimento de paredes e tetos - Determinação do índice de consistência, Assoc. Bras. Normas Técnicas, 2016.

13. ABNT NBR 16541. Argamassa para assentamento e revestimento de paredes e tetos - Preparo da mistura para a realização de ensaios, Assoc. Bras. Normas Técnicas, 2016.

14. Tittarelli F, Giosuè C, Mobili A, di Perna C., Monosi S, Effect of Using Recycled Instead of Virgin EPS 
in Lightweight Mortars. Procedia Eng. 2016 Dec;161:660-665, doi: 10.1016/j.proeng.2016.08.728.

15. Ranjbar MM, Mousavi SY, Strength and durability assessment of self-compacted lightweight concrete containing expanded polystyrene. Mater Struct. 2013 Mar;48(4):1001-1011, doi: 10.1617/s11527-0130210-6.

16. Ramli Sulong NH, Mustapa SAS, Abdul Rashid MK. Application of expanded polystyrene (EPS) in buildings and constructions: A review. J Appl Polym Sci. 2019 Jan;136:47529. doi: 10.1002/app.47529

17. Herki B, M, A, Absorption Characteristics of Lightweight Concrete Containing Densified Polystyrene. Civil Eng J. 2017 Aug;3(8):594-609, doi: 10.28991/cej-2017-00000115

18. Pires R, Desenvolvimento de argamassa com adição de poliestireno expandido [monography. Joinville: Universidade Federal de Santa Catarina; 2017. 52 p. 